Review Article

Journal of Epilepsy Research

pISSN 2233-6249 / eISSN 2233-6257

Received Oct. 1, 2010

Accepted Dec. 2, 2010

Corresponding author: Sang-Ahm Lee Asan Medical Center, University of Ulsan College of Medicine Department of Neurology, Asanbyeongwon-gil 86, Songpa-gu, Seoul 138-736, Korea Tel. +82-2-3010-3445

Fax. $+82-2-474-4691$

E-mail; salee@amc.seoul.kr

\title{
Consensus Guideline for the Assessment of Fitness for Private Driving of Persons with Epilepsy in Korea
}

\author{
Sang-Ahm Lee, MD \\ Department of Neurology, Asan Medical Center, University of Ulsan College of Medicine, Seoul, Korea
}

\begin{abstract}
Korea lacks practical guideline regarding driver's licensing for persons with epilepsy. Therefore, these consensus guidelines would be useful for assessing the fitness of persons with epilepsy for as drivers of personal vehicles in Korea. In the guidelines, a person with chronic epilepsy may receive a driver's license after a seizure-free period of two years. A person with seizures occurring only during sleep or with simple partial seizures (that would not impair driving safety) may receive a driver's license, if no other seizures that might impair their safe driving have occurred for at least two years. A person with newly-diagnosed epilepsy or an isolated seizure may receive a driver's license after a seizure-free period of one year. Driving should be prohibited during withdrawal of medication and for 12 months after withdrawal. These guidelines apply to drivers of personal vehicles but not to commercial drivers. (2011;1:1-5)
\end{abstract}

Key words: Driving; Epilepsy; Seizure

\section{Introduction}

The cumulative incidence rate of epilepsy over an lifetime is at least $4 \%$ of the population, and active epilepsy has a prevalence of 4 to 10 per 1,000 persons in the adult population [1,2].

Among people with epilepsy, not a few drive cars and have their own driver's licenses, but no guidelines exist for assessing their fitness for driving in Korea. In principle, all Korean people with epilepsy are prohibited from driving automobiles, pursuant to Clause 2, Article 70, Chapter 7 of the Driver's License of the Road Traffic Act (enacted on Dec 8, 1992). However, Clauses 1 \& 2, Article 74 of the Act's Enforcement Decree (enacted on Apr 30, 1999) states that even a person with epilepsy may drive a car, upon getting a clinic's medical certificate saying that they can do so.

Such regulations determine absolutely whether the patient may drive a car, but they have no consistency, thus causing confusion due to doctors' substantial differences in judgment with regard to what constitutes driving fitness.

Advanced countries have long since adopted legal regulations for assessing the driving fitness of people with epilepsy, and such countries have recently tended toward relaxing their stringency based on researchers' studies. Hence, it is also desirable for the Republic of Korea to work out the legal standards for assessing the driving fitness of people with epilepsy.
The Korean Epilepsy Society (KES) intends to prepare for the establishment of such legal standards by creating and operating its own guidelines.

\section{The Process of Determining Consensus Guidelines for Assessing Driving Fitness}

Beginning April 2009, the Korean Epilepsy Society conducted a one-month survey of its members, in the first step of working out consensus guidelines for assessing the driving fitness of people with epilepsy. At that time, 123 doctors from neurology (64\%), pediatrics $(24 \%)$, neurosurgery $(6 \%)$, psychiatry $(5 \%)$, and other fields $(1 \%)$ responded to the survey. The respondents comprised $96 \%$ specialists and $4 \%$ residents. Based on the results, the KES held a symposium in June 2009, titled "Driving by People with Epilepsy," and, on November 19, 2009, held a "Public Forum on the Driving Regulations for People with Epilepsy," to collect expert opinions on driving-fitness assessments of people with epilepsy. The KES then created a draft assessment on the basis of the survey, the symposium, and the hearing. In February 2010, the KES collected opinions regarding this draft from the organization's standing commissioners and directors. In March 2010, the Standing Committee decided on the KES's own "Consensus Guidelines for Assessing the Driving Fitness of People with Epilepsy in the Republic 
of Korea."

\section{Consensus Guideline for Assessing the Driving Fitness of People with Epilepsy in the Republic of Korea}

- A driver's license may be issued to a person with chronic active epilepsy if the individual has had no seizures for at least two years.

- A driver's license may be issued to a person with simple partial seizures but no driving problems if the individual has had no seizures that might impair the safety of their driving for at least two years.

- A driver's license may be issued to a person who only experiences seizures during sleep, if the individual has had no waking seizures for at least two years.

- A driver's license may be issued to a person with newly diagnosed epilepsy if the individual has had no seizures for at least one year.

- A driver's license may be issued to a person with an isolated unprovoked seizure if the individual has had no seizures for at least one year.

- A driver's license should not be issued to a person with epilepsy during withdrawal of antiepileptic drugs due to seizure remission, but one may be issued if the individual has had no seizures for at least one year after the complete discontinuation of the antiepileptic drug.

- This guideline applies to drivers of personal vehicles but not to commercial drivers (buses or taxis).

\section{Regulations Regarding the Seizure-free Period of at Least Two Years in Chronic Active Epilepsy}

This consensus guideline says that a driving license may be issued to a person with chronic active epilepsy if the individual has had no seizures for at least two years. This guideline applies to private driving but not to commercial driving. This is based on the results of 2009 KES survey and Korean expert opinions for the driving fitness of people with epilepsy. According to the 2009 KES survey results, $64.2 \%$ of the respondents indicated two years should be the minimum seizure-free period required for issuing a personal driver's license to a person with epilepsy [3].
Such periods differ from country to country and from region to region, but, recently, countries have shown a gradual, general tendency toward easing relevant restrictions. In 2002, Japan released new regulations on driving by people with epilepsy. Japan's preceding regulations completely restricted driving by people with epilepsy regardless of their seizure-free period, but the new regulations allow such individuals to get driver's licenses if they have had no seizures for two years or longer [4]. In 2009, the European Union (EU) released new driving regulations, which lowered the minimum seizure-free period for driving fitness, in a person with chronic epilepsy, from the existing two years to one year [5]. In the United States of America (USA), the minimum seizure-free period differs from state to state; 28 states set the period at 3 to 12 months (median, 6 months), while 23 states have more flexible periods, based on the patients' clinical conditions [6].

Around the world, these gradual reductions in restrictions on driving for people with epilepsy occurred because epilepsy does not have much influence on traffic accident rates. According to a population-based study in the Unites States, $0.2 \%$ of deadly traffic accidents were caused by epilepsy, while $31 \%, 24 \%$, and $4.1 \%$ were caused by drinking, drivers younger than 25 years, and heart disease patients, respectively [7]. According to data at the Belgian Traffic Bureau Website [8], the maximum relative risk of a traffic accident being caused by a person with epilepsy is 1.8. This risk is quite low compared to not only 7.0 , the relative risk for men younger than 25 , but also 3.2 and 3.1, the relative risks for women younger than 25 and people aged 76 years or older, respectively. The relative risk of 1.8 is similar to 2.0, the relative risk for a person on 17 to 19 hours of sleep deprivation; 2.0 , the risk for a person at the lawful intoxication limit $(0.05 \%)$; and 1.6 , for women during menstruation. These data suggest that driving by people with epilepsy is not so dangerous when compared to groups with other characteristics and has a lower relative risk than one might consider.

\section{Assessment of Driving Fitness in Those with Simple Partial Seizures or Seizures during Sleep}

This consensus guideline states that a driver's license may be issued to a person with simple seizures alone but no problems with driving or to a person with seizures that occur only during sleep if the individual goes for at least two years with no seizures that might impair the safety of their driving. According to the KES survey in 
2009, most respondents (78.9\%) advocated differential driving restrictions according to types of epileptic seizures [3]. Among these respondents, $69.1 \%$ and $72.4 \%$ agreed with issuing driver's licenses to people with recurring only simple partial seizures and to people with recurring seizures only during sleep, respectively [3]. The respondents reached these conclusions based on the views of experts, not on scientific proof $[6,9]$, but they followed a global trend seen in the European Union (including the United Kingdom and Germany), the USA, Japan, Australia, etc.

Gibberd and Bateson [10] examined the clinical features and prognoses of 645 epileptic patients experiencing seizures during sleep, and based on this data, Thomas et. al. [11] reported the annual risk of a seizure while awake was $15 \%$ ( $95 \%$ Cl 8.2 to $26.5 \%$ ). Moreover, D'Alessandro et al. [12] prospectively observed persons with pure sleep-related epilepsy for up to six years, concluding that the estimated risk of a seizure while awake was $13 \%$ ( $95 \% \mathrm{Cl} 7$ to $18 \%$ ) during 6 years of follow-up, with the highest risk on a yearly basis occurring in the second year, $5.7 \%(95 \% \mathrm{Cl} 3.0-10.4 \%)$, which was low compared to the rate in an earlier study [10]. The preceding two study results are lower than $20 \%$, the risk at which the $\mathrm{EU}$ allows a person to drive a personal car. However, the study by D'Alessandro et al. [12] is limited in that it excluded frontal lobe epilepsy, and the follow-up period was as short as 2 to 6 years. Accordingly, Thomas et al. [11] systematically reviewed the risks of a seizure while awake in patients with purely sleep-related seizures and concluded that no evidence supports legal regulations allowing a person with pure sleep-related epilepsy to drive a car.

\section{Minimum Seizure-free Period Set at One Year in Newly Diagnosed Epilepsy and Unprovoked Single Seizure}

The consensus guideline states that one year is the minimum seizure-free period after which a driver's license may be issued to a person with newly-diagnosed epilepsy or with an unprovoked, isolated seizure. According to the 2009 KES survey, $56 \%$ and $45 \%$ of respondents were against allowing people with newly diagnosed epilepsy or unprovoked isolated seizure, respectively, to drive cars after a one-year, seizure-free period [3].

After all, the minimum seizure-free period of one year in these situations are based on the data of the previous studies rather than the 2009 KES survey.

The existing studies show that recurrences occur in approximately
$46 \%$ of patients after their first unprovoked single seizure [5]. Such recurrence rates vary according to whether the individuals have any drugs prescribed. The rates were $55.5 \%$ and $33.1 \%$ for persons who received no treatment after single seizure [13-15] and for populations in which at least $80 \%$ received treatment, respectively $[15,16]$. Berg and Shinnar [17] reported that recurrences occurred in $42 \%$ of patients within two years after their first single seizure, based on a meta-analysis of patients with and without drug treatment. Based on a literature review, Beghi et al. [18] said that recurrence rates are 25 to $52 \%$ (38\% on the average) within two years after the first single seizure.

Knowing the timing of recurrence is more important than knowing the rate of recurrence, for judging the driving risks. One study analyzed recurrence rates by period after the first seizure, on an assumption setting the probability of recurrence within two years at $87 \%$ in patients who experienced recurrence, even once in a lifetime, after single seizure $[17,19-21]$. The rates of recurrence were $32 \%$, $53 \%$, and $68 \%$ within 3,6 , and 12 months, respectively $[15,22]$. Therefore, the number that recurs within a year is the average total recurrence $(49 \%)$ times the percentage that has a second seizure in the first year $(68 \%)=33.3 \%$. In contrast, the number that recurs since 1 year after the first seizure is the average total recurrence (49\%) times the percentage $32 \%$ that has a second seizure since 1 year after the first seizure $(100 \%$ minus $68 \%)=15.7 \%$. Additionally, Berg and Shinnar [17] argued through meta-analysis that the rates of recurrence were $8 \%, 5 \%$, and $4 \%$ during the third, fourth and fifth years after the first seizure, respectively.

Hauser et al. [23] examined recurrence rates after 2 or 3 seizures. After 2 seizures, $73 \%$ relapsed in an observation period of 4 years; after 3 seizures, $76 \%$ in an observation period of 3 years. Out of the patients who experienced seizure recurrence, $78 \%$ and $80 \%$ recurred within 12 months after 2 and 3 seizures, respectively. Therefore, the recurrence rate since 12 months after 2 or 3 seizures may be as low as approximately $20 \%$.

In general, the socially-acceptable relative risks for traffic accidents are 2 to 3 [5]. As mentioned above, such values seem socially acceptable considering that the relative risks were 2.0-7.0 for persons younger than 25 , aged 76 or older, sleep-deprived for 17 to 19 hours, and having drunk alcohol within the legal intoxication limit $(0.05 \%)$ [8]. The Chance of an Occurrence of a Seizure in the next Year (COSY) formula calculates such chances using a relative risk. The COSY requires not only a relative risk, but also a deadly accident rate per driver during one year, driving hours per day, and a mortality 
probability in case of a seizure during driving [5]. When relative risks are 2 or 3, COSY are $20 \%$ and $37 \%$, respectively. Therefore EU currently accepts the rates of $20 \%$ to $37 \%$. Comparing to such acceptable COSY, the estimated recurrence rate $15.7 \%$ since 12 months after the first seizure and the estimated relapse rate 20\% since 12 months after 2 or 3 seizures are socially acceptable.

\section{Driving Should be Prohibited during Withdrawal of Medication and for 12 Months after Withdrawal}

This consensus guideline states that the driver's license should not be issued to a person with epilepsy during withdrawal of medication due to seizure freedom, but one may be issued if the individual has had no seizures for at least one year after the complete discontinuation of the antiepileptic drug. According to the 2009 KES survey, most respondents (75.2\%) did not approve of allowing people with epilepsy to drive cars if they began to reduce their antiepileptic drugs to discontinue medication after seizure remission, and the majority of them (61.5\%) only agreed with allowing such people with epilepsy to drive cars if they had been seizure-free for at least one year after completely discontinuation of their antiepileptic drugs [3].

Report of the Quality Standards Subcommittee of the American Academy of Neurology Practice Parameter showed that the seizure recurrence rate is approximately $40 \%$ when medication is discontinued after seizure remission [24]. The relapse rate is highest within one year after the discontinuation. Approximately $30 \%$ of such patients show recurrence within one year [25], and, according to Berg and Shinnar [17], such patients' COSY was 25\% (C.I. $21-30 \%$ ) within the first year after discontinuation of medication, while the COSY was $4 \%$ during the second year. If patients had no seizures for 3, 6, and 12 months after the discontinuation of medication, their COSY was $28 \%, 21 \%$, and $20 \%$, respectively [26]. These findings indicate that driving is permissible if an individual has had no seizures for at least 3 months after the discontinuation of medication. In the United Kingdom and USA, their official guidelines recommend that driving should be prohibited during withdrawal of medication and for 6 months after the complete discontinuation of medication [5,27].

\section{Conclusions}

This KES consensus guideline allows people with epilepsy to drive cars if they have had no seizures, for at least 2 years in cases of chronic active epilepsy, for at least 1 year in cases of unprovoked single seizure or newly diagnosed epilepsy, and for at least 1 year in cases of medication discontinuation due to seizure remission. Recently, driving restrictions for people with epilepsy around the world have eased because epilepsy has not been reported to have much influence on traffic accident rates.

In contrast to such a trend, the driving restrictions in this consensus guideline are somewhat strict, because Korean experts have not altered their stringent views over the last ten years. Such restrictions may continue to exist even in the future, unless experts change their attitudes toward epilepsy and people with epilepsy.

Therefore, it will be necessary to encourage doctors to change their views on driving by people with epilepsy, through symposiums and studies about safe driving by people with epilepsy.

\section{Acknowledgment}

This article was written on behalf of the Korean Epilepsy Society, chaired by Dr. Sang-Do Yi.

\section{References}

1. Hauser WA, Annegers JF, Rocca WA. Descriptive epidemiology of epilepsy: contributions of population-based studies from Rochester, Minnesota. Mayo Clin Proc 1996;71:576-86.

2. Goodridge GM, Shorvon SD. Epileptic seizures in a population of $6000 . \mathrm{Br}$ Med J 1983;287:645-7.

3. The Social Committee of Korean Epilepsy Society. Driving in patients with epilepsy: doctor's perspective. J Korean Epilepsy Soc 2010;14:1-5.

4. Inoue $\mathrm{Y}$, Ito $\mathrm{M}$, Kurihara $\mathrm{M}$, Morimoto $\mathrm{K}$; Commission on Legal Affairs, Japan Epilepsy Society (Japan chapter of ILAE). Epilepsy and driving in Japan. Epilepsia 2004;45:1630-5.

5. An advisory board to the Driving Licence Committee of the European Union. Epilepsy and driving in Europe: a report of the Second European Working Group on Epilepsy and Driving. 3 April 2005.

6. Krauss GL, Ampaw L, Krumholz A. Individual state driving restrictions for people with epilepsy in the US. Neurology 2001;57:1780-5.

7. Sheth SG, Krauss G, Krumholz A, Li G. Mortality in epilepsy: driving fatalities vs. other causes of death in patients with epilepsy. Neurology 2004:63:1002-7.

8. Belgian Traffic Data 2001: http://www.statbel.fgov.be/figures/d37_nl.asp 
9. American Academy of Neurology, American Epilepsy Society and Epilepsy Society; Consensus statement, statutory provisions and model regulations regarding driver licensing and epilepsy. Epilepsia 1994;35:696-705.

10. Gibberd FB, Bateson MC. Sleep epilepsy: its pattern and prognosis. $\mathrm{Br}$ Med J 1974;2:403-5.

11. Thomas RH, King WH, Johnston JA. Awake seizures after pure sleep-related epilepsy: a systemic review and implications for driving law. J Neurol Neurosurg Psychiatry 2010;81:130-5.

12. D'Alessandro R, Guarino $M, G r e c o G$, et.al. Risk of seizures while awake in pure sleep epilepsies: a prospective study. Neurology 2004;62:254-7.

13. Elwes $R$, Chesterman P, Reynolds EH. Prognosis after first tonic-clonic seizure. Lancet 1985;2:752-3.

14. Stroink H, Brouwer OF, Arts WF, Geerts AT, Peters AC, Van Donselaar CA. The first unprovoked, untreated seizure in childhood: a hospital based study of the accuracy of the diagnosis, rate of recurrence, and long term outcome after recurrence. Dutch study of epilepsy in childhood. J Neurol Neurosurg Psychiatry 1998;64:595-600.

15. First Seizure Trial Group. Randomized clinical trial on the efficacy of antiepileptic drugs in reducing the risk of relapse after a first unprovoked tonic-clonic seizure. Neurology 1993;43:478-83.

16. Camfield P, Camfield C, Dooley J, Smith E, Garner B. A randomized study of carbamazepine versus no medication after a first unprovoked seizure in childhood. Neurology 1989;39:851-2.

17. Berg A, Shinnar $S$. The risk of seizure recurrence following a first unprovoked seizure: a quantitative review. Neurology 1991;41:965-72.

18. Beghi E, Berg A, Hauser A. Treatment of single seizures. In: Engel J Jr, Pedley TA, eds. Epilepsy: a comprehensive textbook. Philadelphia:
Lippincott-Raven Publishers. 1997.

19. Hart YM, Sander JW, Johnson AL, Shorvon SD. National General Practice Study of Epilepsy: recurrence after a first seizure. Lancet 1990;336:1271-4.

20. Shinnar S, Berg AT, O'Dell C, Newstein D, Moshe SL, Hauser WA. Predictors of multiple seizures in a cohort of children prospectively followed from the time of their first unprovoked seizure. Ann Neurol 2000;48:140-7.

21. Hui AC, Tang A, Wong KS, Mok V, Kay R. Recurrence After a First Untreated Seizure in the Hong Kong Chinese Population. Epilepsia 2001;42:94-7.

22. Annegers JF, Shirts SB, Hauser WA, Kurland LT. Risk of recurrence after an initial unprovoked seizure. Epilepsia 1986;27:43-50.

23. Hauser WA, Rich SS, Lee JR, Annegers JF, Anderson VE. Risk of recurrent seizures after two unprovoked seizures. N Engl J Med 1998;338:429-34.

24. Report of the Quality Standards Subcommitte of the American Academy of Neurology Practice Parameter. A guideline for discontinuing antiepileptic drugs in seizure-free patients-Summary statement. Neurology 1996;47:600-2.

25. Yale SH, Hansotia P, Knapp D, Ehrfurth J. Neurologic conditions: assessing medical fitness to drive. Clin Med Res 2003;1:177-88.

26. Sonnen $A E$, the European Working Group. Epilepsy and Driving Proceedings First European Workshop epilepsy and Driving Licences Group 1. IBE May 1995.

27. American Academy of Neurology position statement on physician reporting on medical conditions that may affect driving competence. Neurology 2007;68:1174-7. 